\title{
LAS CAUSAS DE LOS MOTIVOS DE EGUREN. BASES CRÍTICAS, PLANTEAMIENTOS ESTÉTICOS E IDEAS SOBRE LA LITERATURA EN MOTIVOS DE JOSÉ MARÍA EGUREN
}

\author{
THE CAUSES OF EGUREN'S MOTIVOS. CRITICAL BASES, \\ AESTHETIC EXPOSITIONS AND IDEAS ABOUT THE LITERATURE \\ IN JOSÉ MARÍA EGUREN'S MOTIVOS \\ José R. Valles Calatrava \\ Universidad de Almería. Almería, España \\ Jrvalles@ual.es
}

\begin{abstract}
Resumen: Este artículo analiza una de las obras menos estudiadas del gran poeta peruano José María Eguren, sus textos en prosa que luego fueron reunidos bajo el nombre de Motivos. El libro contiene treinta y ocho bellos escritos de naturaleza panestética que hay que filiar en la crítica impresionista, pero con un corpus de nociones teóricas que tienen su origen en el Romanticismo alemán y parcialmente en el Simbolismo francés. Conviene resaltar asimismo en ellos la impronta universal, atractiva y muy personal que les da su autor.
\end{abstract}

Palabras clave: Literatura peruana simbolista, José María Eguren, crítica literaria impresionista, estética literaria.

\begin{abstract}
This article analyzes one of the least studied works of the great Peruvian poet José María Eguren, his prose texts which were later assembled under the name of Motivos. The book contains thirty-eight beautiful writings of a panaesthetic nature belonging to Impressionistic Criticism, but with a corpus of theoretical notions which have their origin in German Romanticism and partially in French Symbolism. It suits to highlight also the universal, attractive and very personal stamp that his author gives them.
\end{abstract}

Keywords: Peruvian symbolist literature, José María Eguren, Impressionistic Literary Criticism, literary aesthetics.

Recibido: 17.11.2015. Aceptado: 01.03.2016. 


\section{Orígenes}

La línea es emoción y belleza. Simple y paradojal, une y separa; es limitación e infinitud [...] La recta es una liberación, una senda al infinito || La miniatura es el espejo de la infancia [...] Los juguetes son una simulación liliputiense de la vida || La mujer es una flor, el insecto una joya.

$\mathrm{E}$ STAS FRASES DE José María Eguren (1874-1942), contenidas en tres de los distintos ensayos que conforman el libro comúnmente conocido como Motivos, quieren ser solo un inicial botón de muestra del personal tono, forma y visión que impregnan estos textos, referidos estéticamente al arte y a la naturaleza y que constituyen, al biselar el juicio mediante la emoción y originalidad expresiva y al tamizar la visión de mundo exterior a través de la subjetividad, uno de los máximos ejemplos hispánicos de la cercanía entre el ensayo y la lírica a la par que de la crítica impresionista.

Los escritos estéticos de Eguren, que sin duda se erigen en no solo la parte más importante sino también la más amplia de su pensamiento escrito y su prosa (existen asimismo otros varios trabajos y un cuento), son un corpus bastante reducido, que no alcanza la cuarentena de ensayos de reducida extensión y aparecieron entre los años veinte y treinta de la pasada centuria en distintos diarios (El Comercio, La Noche) y revistas (Prometeo, Social, La revista semanal, Revista de educación, Amaru) peruanas. Fueron editados juntos por primera vez (Oviedo, 2007) en 1959 y bajo el título de Motivos estéticos, por Estuardo Núñez, padre, según García-Bedoya (2009), de la crítica peruana moderna, de enfoque estilístico y centrada primordialmente en el texto, que propició con su Tesis Doctoral y primer libro, de 1932, precisamente sobre La poesía de Eguren. La posterior edición de Silva-Santisteban (1997), que los integra en sus Obras completas de Eguren, añade un par de textos rescatados y publicados por Westphalen en 1969 en la revista Amaru. Finalmente, han sido reeditados asimismo en España, en Huerga y Fierro, por Juan Manuel Bonet (2008), sin alteraciones sustanciales en cuanto al contenido, salvo la de añadir La sala ambarina y La gala de Francia -que Silva-Santisteban colocó fuera de los Motivos, pero que podrían efectivamente formar parte de los mismos- bajo el epígrafe Otras prosas. 


\section{Contenido}

Tal y como figuran en las ediciones de Silva-Santisteban (1997) y de Bonet (2008), componen Motivos 38 breves ensayos: Sintonismo, Eufonía y canción, La lámpara de la mente, Línea, forma, creacionismo, Las ventanas de la tarde, De estética infantil, El diario íntimo, La belleza, Metafísica de la belleza, La emoción del celaje, El olvido de los recuerdos, Las estampas de la vida, Tropical, La realidad del instante, La gracia, Notas rusticanas, Arte inmediato, Paisaje mínimo, La esperanza, Filosofía del objetivo, La elegancia, Visión nocturna, El nuevo anhelo, La piedad, Las terrazas, Expresiones líricas, El ideal de la vida, El ideal de la muerte, Ideas extensivas, Sinfonía del bosque, Los finales, Noche azul, Intelección, Noches limeñas, Los caballos de Chagall, Pedrería del mar, Ideación y La impresión lejana.

El tratamiento panartístico no solo de la literatura y el arte sino incluso de la naturaleza o de la infancia, la densidad y la acumulación de ideas expuestas casi como pinceladas impresionistas más que como razonamientos desarrollados y la dimensión estética y el tono evocativo son algunos de los rasgos que saltan a la vista a la hora de leer estos textos.

Bonet resalta en ellos la vinculación architextual primordial con la lírica de todo el libro en general, y particularmente de muchos fragmentos del mismo:

Motivos es un libro de prosas de carácter principalmente ensayístico [...], pero en la mayor parte de las cuales se cuelan, por fortuna, la subjetividad del autor, sus vivencias, sus recuerdos, muchos de ellos de la infancia, de la hacienda [...] Casi poemas a veces. Poemas en prosa [...] Decenas de esas fórmulas, en Motivos, podrían ser consideradas como poéticas de su autor (Bonet, 2008: 9, 13 y 14).

Y Silva-Santisteban destaca su intención estética y carácter de ideación carente de las características comunes de la prosa científica y racional propia del ensayo:

Los textos de Motivos [...] son ajenos a las características de la prosa común, su intención es evocativa o estética y en ellos Eguren trata de captar el desenvolvimiento psicológico de la naturaleza y el arte, escogiendo 
el medio de aprehensión cartesiano. [...] lo que, aparentemente, es un uso continuo de elipsis en el discurso de su prosa puede reconocerse como un artificio lingüístico y una rápida movilidad en el hilo conductor de las ideas. Puede añadirse también que más que una ilación en la expresión de las ideas, existe un tipo de ilación metafórica. Su prosa carece de la racionalidad que encontramos no solo en la prosa expositiva sino también a través de los ejemplos de casi toda la literatura española (Silva-Santisteban, 1997: XLVII).

Coincidiendo con ellos en lo fundamental, considero que estos textos son tanto motivos como ensayos, pero en el más auténtico, profundo y original sentido de ambas palabras. Motivos porque, en la idea del término leitmotiv creado por Von Wolzugen, los temas a tratar por Eguren no son tanto el objeto del estudio reflexivo y centro del ensayo cuanto meros causantes o motores de la actividad artística y meros referentes, casi anécdotas, para exponer acentuadamente su visión o sentimiento personal ante distintos fenómenos, naturales y artísticos, no solo diferentes sino de órdenes distintos, que no obstante aparecen vinculados por una dimensión estética y un mismo juicio estético tan omnisensible como pluritemático. Ensayos porque son juicios estéticos en prosa pero de un marcado carácter personal y subjetivo, esto es, cuasilírico: en ellos se vuelca y extiende la interioridad autoral directa, aunque expresándose en un modelo de base kantiana de exposición del juicio crítico individual, en este caso estético.

\section{Poesía de Eguren y lenguaje de Motivos}

Eclipsado en su momento por el humanismo universal de Vallejo y la fuerza modernista de Santos Chocano, José María Eguren, hoy tan generalmente desconocido en España como famoso en el Perú, fue no solo uno de los más excelsos poetas simbolistas -acaso el autor más original de esta tendencia en lengua española- sino asimismo, como poeta moderno y cosmopolita (Veres, 2011), uno de los grandes fundadores de la lírica contemporánea peruana. Según Marco Martos, Presidente de la Academia Peruana de la Lengua y uno de los promotores y organizadores en noviembre de 2011 del interesante Congreso Internacional José María Eguren y la modernización poética en el Perú, su obra lírica, contenida en Simbólicas (1911), 
La canción de las figuras (1916), Sombra (1916) y Rondinelas (1929), es "música en el mejor sentido del término, tiene un tema central rítmico y numerosas variaciones que van acomodando su armonía a una polisemia de resonancias muy variadas. Es concentración. Dice más con menos palabras" (Martos, 2009: 2).

La desrealización, la sugerencia y el símbolo se dan la mano en una poesía contemporánea y moderna, cercana al romanticismo de Novalis y, aún más, al simbolismo de Verlaine y Mallarmé, pero también tocada por el transfigurador dedo personal del sentido panestético y la formación pluriartística del propio poeta peruano y su especialísimo y original uso del leguaje -esteticista, colorista y arcaizante- y la métrica: como dice Oviedo (2007: 86), "el efecto final que crea esa retórica es distinto porque está interiorizada por una sensibilidad marcadamente distinta".

Y se extiende igualmente a todos los textos de Motivos ese peculiar y virtuoso, encandilador y subyugante, manejo del lenguaje, con la frase muy corta y la frecuente aproximación a la lírica, haciendo poemas en prosa casi en algunas ocasiones, acuñando paradójicas frases que encierran certeras y sugerentes ideas que se clavan en la memoria como si de inolvidables y atractivos títulos se tratara; he aquí, por ejemplo, algunas, salpicadas, referidas al arte:

La poesía es la revelación del misterio por la verdad del sentimiento || La forma es dolorosa, porque circunscribe y concreta || La obra de arte es un dictado misterioso; la voluntad lleva al fracaso || La belleza es de recuerdo || El modo inmediato de la poesía es el canto lírico y el diario íntimo.

En este original y singular empleo del lenguaje, hay que resaltar las metáforas originales y novedosas (sobre todo, $A$ de $B$ ), que se extienden por todo el volumen, pero que incluso invaden gran parte de los títulos de los Motivos: La lámpara de la mente, Las ventanas de la tarde, La emoción del [gris] celaje, El olvido de los recuerdos, Las estampas de la vida, La realidad del instante, Filosofía del objetivo, Sinfonía del bosque y Pedrería del mar. Sorprenden especialmente la facilidad para la personal creación de palabras mediante la arcaización -harmonía, medioeval- y sobre todo mediante derivación: ocurre muy frecuentemente en adjetivos -divinal, bosquecino, antañero, silvoso, extasista, glorietal, melodial, perlino-, 
pero también con verbos -malabarear, violetizar, viñetear- y sustantivos -celestidad, magiquez-, a veces usados también como adjetivos por adjunción -un ave casi viento-.

Así pues, como se ve, inseparablemente del Eguren poeta -y pintor, y músico, y fotógrafo-, se halla el Eguren ensayista, autor de unos preciosos e interesantes textos que atrapan no solo por la originalidad de sus planteamientos y la belleza de su forma sino asimismo por la modernidad de muchas de sus ideas, siempre alusiones y referencias más que razonamientos lógicos, siempre enormemente subjetivas y originales, siempre aventuras de su alma ante distintos temas que suscitan su sentimiento estético. Por eso, en un artículo que reinterpretaba la base temática inspiratoria de Los reyes rojos (Valles, 2011), su motivo, compartía la general adscripción de la poesía de Eguren al simbolismo destacada por casi todos los críticos (Areta, 2009; Mariátegui, 1996; Martos, 2009; González Vigil, 2011; Oviedo, 1997, 2007; Silva-Santisteban, 2002; Veres, 2011), siempre con matizaciones respecto a su particular sello, pero aludía también al sustrato impresionista presente en Motivos y a la dimensión ensayístico-artística del mismo y su planteamiento estético panartístico, coherente con su formación no solo poética sino pictórica (Gonzales Alvarado, 2006), musical (Silva-Santisteban, 2002) e incluso fotográfica.

\section{Bases críticas y planteamientos estéticos}

En realidad, si bien en la poesía de Eguren hay coincidencia entre los estudiosos respecto al modelo simbolista básico, en sus ensayos estéticos, $\mathrm{Mo}^{-}$ tivos, se han destacado múltiples características, sin duda acertadamente casi siempre, pero se echa de menos - pese a la marcada impronta personal- la filiación con la matriz crítica impresionista que, explícita o implícitamente, viene a calar y trascender su pensamiento artístico individual, pese a ser este muy lírico y original y particularmente resaltable -junto al de Azorín, quien acentuaba precisamente la condición temporal y personal de los valores estéticos (Zuleta, 1966: 138)- dentro de tal panorama crítico desarrollado en lengua española en las primeras décadas del siglo XX.

Así pues, considerando lo dicho a propósito de los ensayos y los motivos, Eguren, exponiendo su juicio crítico y sentimiento estético respecto a 
ciertas obras, temas, artes, ideas o elementos de la naturaleza o el recuerdo, no hace tanto crítica sobre arte como un verdadero e idéntico arte, metaarte en suma si se me permite el neologismo. Y esta es justamente una de las más acusadas peculiaridades de la crítica impresionista, pues, como escribe Wahnón, “para el impresionista, la obra crítica es también una obra artística, no una obra teórica, porque no se puede teorizar con pretensiones científicas sobre algo que es fruto de la fantasía y la sensibilidad" (Wahnón, 1991: 66).

De hecho, cuando Eguren proyecta tan lírica como creativamente sus juicios, la matriz impresionista en el libro se muestra tan patente que a veces uno ve materializarse en el mismo la idea de Jules Lemaître -al parecer el adaptador del término impresionismo, tomado de la pintura, a la crítica literaria- de la variación de la imagen de todas las obras literarias cuando desfilan ante el espejo de nuestra alma ${ }^{1}$, o, todavía más, de las opiniones de Anatole France primero sobre cómo el crítico, al hablar de un autor o una obra maestra, en el fondo no habla sino de sí mismo y después sobre cómo la literatura, al igual que el paisaje, se transforma en los ojos que lo ven y las almas que lo conciben².

Se ha incidido mucho también en la dimensión panestética y en la variedad poligráfica y temática, incluso extraartística, del conjunto de ensayos de Eguren. Al margen de las artes, trata de la naturaleza, el paisaje o el cielo limeño, el sueño, las líneas y las formas, la fantasía, la infancia y las miniaturas, las diversas -misteriosas o luminosas- niñas; dentro de las artes, alude a la literatura en sus diversas formas, pero también a la pintura, el jazz o el ballet, el cinema, y, ya monográficamente, se centra en la estética,

"Les oeuvres défilent devant le miroir de notre esprit; mais, comme le défilé est long, le miroir se modifie dans l'intervalle, et, quand par hasard la même oeuvre revient, elle n'y projette plus la même image" (Lemaître, Les Contemporains, 1887-1899, T. II: 84; en Wellek, 1988: 34).

2 "Il n'y a pas plus de critique objective quíl n'y a d'art objectif, et tous ceux qui se flattent de mettre autre chose qu'eux-mêmes dans leur oeuvre sont dupes de la plus fallacieuse illusion. La vérité est qu'on ne sort jamais de soi-même [...] Pour être franc, le critique devrait dire: -Messieurs, je vais parler de moi à propos de Shakespeare, à propos de Racine, ou de Pascal ou de Goethe" [... "Tout libre a autant d'exemplaires different qu'il a de lecteurs et qu'un poème, comme un paysage, se transforme dans tous les yeux qui le voient, dans toutes les âmes qui le conçoivent" (France, La vie littéraire, 1888, I: 5-6; en Wellek, 1988: 616). 
la belleza, el diario, la línea y el creacionismo, los finales, el nuevo arte sintético, o los sugerentes trabajos sobre la fotografía y la música (Filosofía del objetivo y Sintonismo, el primer escrito). Este planteamiento pluriestético, vinculado a "una estética del sentimiento con carácter eminentemente individualista" procede de un idealismo neoplatónico replanteado por Schiller y difundido en el ámbito hispánico tras la traducción de la Retórica de Blair (Wahnón, 1991: 53).

En general, cabe decir que los mayores y más originales aciertos de Eguren se encuentran en el mencionado sentido panestético de contemplación y vivencia del mundo atrapado dentro de Motivos, en los frecuentísimos accesos al lirismo de gran calidad y en su sentido artístico extraterritorial de modernidad, universalidad y actualidad, que contrasta actitudinalmente con su vida, siempre limeña.

Sorprende menos, sin embargo, lo que a veces más ha llamado la atención: el carácter misterioso, fantástico o críptico y la importancia de la evocación o la sugerencia, tan repetido, proviene, como ya advirtió SilvaSantisteban (1997: XXXIV) -quien también vincula su personificación de la naturaleza a la falacia patética de John Ruskin (XLVIII)-, de la doctrina de las correspondencias del místico sueco Emanuel Swedenborg aunque filtrada por su aplicación a la poesía simbolista por Baudelaire: la idea central consiste, según Viñas,

en afirmar que el mundo sensible es un sistema de símbolos que evoca realidades ocultas e inaccesibles, con lo cual el universo entero es visto [...] como una vasta red de correspondencias. El texto más famoso de Baudelaire sobre este tema es el soneto Correspondances, con lo cual se advierte cómo efectivamente los poetas simbolistas comunican sus ideas teórico-críticas desde sus propios poemas (Viñas, 2002: 352).

Asimismo, y además de las preferencias personales de Eguren, toda la fascinación por la teoría musical, así como toda la temática mitológica nórdica y medieval, común al imaginario simbolista, proviene de Wagner (Viñas, 2002: 351), al igual que tiene sus raíces en Verlaine la iconografía sentimental de las niñas, "parques abandonados, fuentes musgosas y caminos cubiertos de hojas muertas, claros de luna, arlequines y amantes melancólicos" (Todó, 1987: 16).

Gonzales Alvarado, tras incidir en la sensibilidad pura y diferente de 
Eguren tanto respecto a la entonces dominante como respecto a la próxima del arte comprometido, plantea la importancia de las sombras y el misterio, la infancia y el juego y el mundo interior y privado en el universo poético de Eguren y recuerda la inseparabilidad de su pintura y su poesía:

Eguren, por medio de su arte (plástico-literario), construye las utopíassueño, según la terminología eliasiana, aunque quizás sea mejor decir las utopías-ensueño. Sus acuarelas, en las que predomina el azul y la noche, las sombras y lo enigmático, las figuras alegóricas y fantasmales; y sus rimas, que transmiten un mundo infantil, pero no necesariamente feliz y armonioso, crean, ambos, como lenguajes inseparables, un mundo fantástico, vaporoso e inasible (Gonzales Alvarado, 2006: 3).

\section{Ideas de Eguren sobre la literatura}

No solo no es la literatura el único tema de Motivos sino ni siquiera el más importante: la naturaleza, la belleza, lo infantil, la música y la pintura son cuantitativamente más trascendentes, e incluso el cine y la fotografía (Filosofía del objetivo) son abordados en los textos del volumen. Sin embargo, a lo largo de la obra aparecen diseminadas algunas más personales que originales ideas sobre la literatura cuya identificación constituye el objeto de este epígrafe.

Importante es el tercer ensayo, La lámpara de la mente, que defiende la fantasía como emoción y condición y base esencial de la creación estética: entre los ejemplos de todo orden artístico, centrados sobre todo en el ámbito oriental y medieval, cita formas literarias muy consonantes con esos mundos: los cuentos fabulosos de Las mil y una noches, la genialidad imaginativa de La Divina Comedia pese a su "imaginismo dionisíaco" (Eguren, en Silva-Santisteban, 1997: 198; en Bonet, 2008: 38), la tradición y leyenda medieval de Santa Hilda de Courlande recogida por Jean Lorrain. Las bases fundacionales de estas ideas de Eguren habría que buscarlas en el romanticismo alemán -al igual que la del artista o creador-genio, subyacente a toda su estética-: como planteé en otro lugar (Valles, 1994: 48-50), los hermanos Federico y Augusto Schlegel defendieron, al igual que Schelling, el roman, la novela fantástica, incluyendo en el mismo no solo las novelas no realistas sino los mitos, romances, relatos caballerescos 
y exóticos, etc; y Novalis y los hermanos Grimm vincularon el carácter del roman con el cuento primitivo, popular y fantástico.

Al genio se refiere también varias veces en El nuevo anhelo, dedicado al modernismo, en su sentido de arte más actual y novedoso. Su tesis es que el arte, comunicativo sociológicamente pero emotivo, sintético y aristocrático en su esencia, es esencialmente captado por el genio y plasmado artísticamente en la modernidad, que tematiza lo actual y novedoso en cada época: como en el anterior caso, la filiación romántica de las ideas es meridiana, añadiéndose aquí el concepto de modernidad como presenticidad también de origen romántico pero desarrollado por Stendhal y Baudelaire. En distintos momentos históricos, han sido modernos, Cervantes, el cubismo y los versos modernistas y vanguardistas, Proust y finalmente el teatro ruso constructivista, el cinema, el surrealismo y el expresionismo alemán; así, por ejemplo, Cervantes ${ }^{3}$ fue un vanguardista de su tiempo, pues "combatió el pasadismo de su tiempo, los libros de caballería” y quebró los moldes latinos y de la escritura grave de su tiempo introduciendo un arte risueño; Proust fue un genio por prescindir "del argumento, el episodio y la anécdota, para plasmar la vida auténtica, que es rítmica como el latido, y que, mentalmente, es un diorama de sensaciones y pensamientos, o banalidades inconscientes" (Eguren, en Silva-Santisteban, 1997: 242 y 243; en Bonet, 2008: 150-151 y 153-154).

Casi los mismos planteamientos -genio, alma, síntesis, modernidad, belleza natural y artística- son los que se mencionan en las pocas líneas que ensalzan a Proust, Breton y Valéry en las poquísimas líneas dedicadas a la literatura -algunas más a la música y la pintura- en La belleza. La condensación y la síntesis son también la clave del arte moderno y de vanguardia, en general, en Paisaje mínimo, en un texto que es también un breviario de su teoría estética:

Los bizantinos, los románticos, los benedictinos, esbozaban prolijamente, eran lentos artífices. Los modernistas son sintéticos; un pensamiento en una línea. El artista de vanguardia es un viajero que simplifica su emoción y aporta, únicamente, los sentimientos más vivos de su carre-

${ }^{3}$ Justamente al genio de Cervantes dedica Eguren un brevísimo pero sugerente texto recogido en Artículos y notas por Silva-Santisteban (1997: 283-284). 
ra mortal, le falta tiempo para los secundarios. Basta haber sentido un instante en la vida, agudizada la belleza pura, y exteriorizarla ingenuamente, para que la obra de arte perdure; basta que por el instinto social ofrezcamos nuestros íntimos sentires para que miremos terminada nuestra misión estética. Los vanguardistas prefieren extremar la síntesis (Eguren, en Silva-Santisteban, 1997: 233; en Bonet, 2008: 126).

A la lírica, y en concreto a la modalidad del diario, se dedica fundamentalmente El diario íntimo, un género marcado por la radical expresión de la subjetividad autoral que, como bien observa Eguren, además incide en la sinceridad y verdad de esta "confidencia del autor al papel” (Eguren, en Silva-Santisteban, 1997: 207; en Bonet, 2008: 60). Resalta la comparación de las novelas poéticas como Childe Harold o sin argumento como El Quijote o La Divina Comedia con el diario por su "composición etápica”, pero también se indica con acierto, asimismo por su estructura, que "todo relato viajero es un diario" (Eguren, en Silva-Santisteban, 1997: 207; en Bonet, 2008: 61). También se define el diario íntimo en oposición a la novela: esta ofrece la presunción de un mundo aparte y por ello se frustra en muchas ocasiones por falta de penetración humana y por ciertos diálogos o pasajes banales; el diario en cambio es libre y cierto, más independiente y sincero, y además puede suponer -en cierta medida empleando inconscientemente el concepto de novela familiar de Freud, desarrollado por Marthe Robert"la novela de un solo personaje" (Eguren, en Silva-Santisteban, 1997: 207; en Bonet, 2008: 61-62). La vinculación del diario íntimo con la autobiografía, con la que comparte una identificación entre el yo autoral, narrativo y actoral, pero su deslinde y su enraizamiento en la lírica por su origen subjetivo y expresivo y su dimensión más personal y sincera, más inmediata y temporalmente acotada, muestra en mi opinión una idea bastante moderna y acertada del mismo.

Sobre el mismo asunto incide Arte inmediato, aunque en este caso se cita la condición del género novelesco, que se caracteriza por su carácter objetivo y de penetración de la humanidad, en oposición a la poesía [lírica]: "El modo inmediato de la poesía es el canto lírico y el diario íntimo. La novela es una objetivación inmediata. El novelista es un penetrador de la humanidad" (Eguren, en Silva-Santisteban, 1997: 230; en Bonet, 2008: 120). El ensayo comienza y termina oponiendo, en relación al sentimiento 
y la naturaleza, la música y la pintura a la poesía, "música, colorido e imagen; arte inmediato cuando funde estos valores en un solo movimiento" (Eguren, en Silva-Santisteban, 1997: 230; en Bonet, 2008: 119), y el poeta

dice su emoción en una espontaneidad musical de palabra, en la esencia misma de su objetivo ideal. La palabra hace comprender la belleza y la música sentirla. La literatura es como la inteligencia, un instrumento no una causa, el lado físico del cual no puede prescindir el arte (Eguren, en Silva-Santisteban, 1997: 229; en Bonet, 2008: 118).

Ideas extensivas es un -relativamente- amplio ensayo sobre el carácter sintético e ideológico de la esencia de todo arte pese a desarrollarse y extenderse en una determinada forma. En cuanto a la poesía, estas son las palabras del poeta peruano:

La obra de arte es un dictado misterioso. La voluntad lleva al fracaso [...] No es idea extensiva, libre como el arte, como la poesía. Todo arte es poético; un vuelo fino y absoluto; su libertad corta la red, la métrica y la rima son sus pajes. El ideal sería prescindir del número y la forma; pero existe un ritmo vital, que se expande internamente. Ciertas poesías apolíneas son rítmicas como los versos de niños y aciertos inmortales. Las ideas únicamente estéticas de la poesía son infinitas por extensión y libertad (Eguren, en Silva-Santisteban, 1997: 255; en Bonet, 2008: 185).

No hay demasiadas referencias importantes más a la literatura en el resto de textos que componen Motivos. En La gracia se alude al humorismo en la literatura, fundamentalmente al humano e inmortal, tal como se encontraría en Cervantes, Molière, Twain, Chesterton y Queiroz, y se compara este con las peculiaridades de lo que Rubén Darío denominó la gracia limeña. Pese a su nombre, Expresiones líricas no contiene más alusión a la literatura que su cita del contradictorio Byron, violento en [Las peregrinaciones de] Childe Harold y melodioso y tenue en sus versos de amor. Y Los finales apenas recoge breves referencias a San Juan de la Cruz, Dante, Homero, Valmore, Lamartine y Verlaine para ilustrar nuevamente sus tesis románticas sobre el genio, la síntesis y la hegeliana idea de la literatura como plasmación del absoluto (Eguren, en Silva-Santisteban, 1997: 224225, 249 y 259-260; en Bonet, 2008: 105-106, 168 y 196-200). 


\section{Conclusiones}

Si bien las ideas sobre la literatura diseminadas por Motivos son escasas y asistemáticas, más bien bellas y artísticas intuiciones fugaces o expresiones anímicas -aventuras del alma- en coherencia con el modelo crítico del impresionismo subyacente al libro, el entramado ideológico, teórico y estético de la visión de la literatura y el arte de Eguren está profundamente endeudado con el romanticismo, básicamente alemán, aunque casi nunca sus conceptos le lleguen de primera mano, sino sobre todo a través de sus lecturas francesas, pues sus principales modelos literarios e incluso la noción de modernidad como actualidad e incluso presenticidad tienen ese origen nacional. Pero la estética del sentimiento enraizado en lo individual se difunde con la recodificación platónica de Schiller, padre también del aprecio por la poesía ingenua y sentimental ${ }^{4}$, las ideas sobre el absoluto y la belleza son hegelianas, la fascinación por la música y la mitología medieval y nórdica tiene origen wagneriano, la pasión por la nocturnidad, la musicalidad y la fantasía poética hunde sus raíces en Novalis, el enlace teosóficosimbólico parte del sueco Swedenborg aunque se conozca mediante su aplicación artística por el soneto "Correspondencias" de Las flores del mal de Baudelaire, y los temas de las niñas y la naturaleza decadente provienen de Verlaine; el aprecio por lo fantástico, por las raíces medievales y exóticas y por el genio recorre prácticamente todo el romanticismo alemán, como las nociones de Volkgeist y Zeitgeist, que sin embargo deja de lado siempre el poeta peruano ante su apuesta por el genio y lo absoluto.

Independientemente de lo anterior, Motivos constituye un texto no solo moderno y universal sino encantador y subyugante, atractivo para la lectura, lleno de accesos al lirismo y de frases memorables, sorprendente por su planteamiento panestético y la originalidad de las fórmulas personales de Eguren para expresar todo el entramado teórico, crítico y estético arriba desvelado.

${ }^{4}$ Véase la casi literalidad de esta expresión en el fragmento reproducido de Paisaje mínimo. 


\section{Referencias}

Areta Marigó, G. (2009). Los discípulos de José María Eguren. Libros\&Artes, VIII, 36-37, cuaderno central “José María Eguren (1874-1942)”, 6-12.

Bonet, J.M. (2008). Prólogo. En José María Eguren, Motivos (pp. 7-19). Madrid: Huerga y Fierro editores.

Eguren, J.M. (s.f.). Motivos. En R. Silva-Santisteban (ed. e introd.) (1997), José María Eguren. Obras completas (pp. 191-275). Lima: Banco de Crédito del Perú. Y en J.M. Bonet (ed. e introd.) (2008), José María Eguren, Motivos (pp. 21-237). Madrid: Huerga y Fierro Editores.

García-Bedoya, C. (2009). Estuardo Núñez: un siglo fructífero. Letras, LXXX, $115,165-176$.

Gonzales Alvarado, O. (2006). La utopía de José María Eguren, 1-5. Disponible en http://www.librosperuanos.com/autores/articulo/oooooooo559/Lautopia-de-Jose-Maria-Eguren.

González Vigil, R. (2011). El blasón de José María Eguren. Martín, 24, año XI, 39-45.

Mariátegui, J.C. (1996). Eguren. En "El proceso de la literatura", Siete ensayos de interpretación de la realidad peruana (pp. 191-199). Lima: Empresa Editora Amauta.

Martos, M. (2009). José María Eguren. La palabra dicha a media voz. Libros\&Artes, VIII, 36-37, cuaderno central "José María Eguren (18741942)", 2-3.

Oviedo, J.M. (1997). Los enigmas de Eguren. Vuelta, 252, noviembre, 15-18. . (2007). Eguren. En Historia de la literatura hispanoamericana, 3: postmodernismo, vanguardia, regionalismo (pp. 84-91). Madrid: Alianza Editorial.

Silva-Santisteban, R. (1997). Prólogo: José María Eguren. En José María Eguren, Obras completas (pp. XIII-LV). Lima: Banco de Crédito del Perú.

. (2002). La poesía de José María Eguren: modernismo y modernidad. Boletín de la Academia Peruana de la Lengua, XXXV, 47-66.

Todó, Ll.M. (1987). El simbolismo. El nacimiento de la poesía moderna. Barcelona: Montesinos.

Valles, J.R. (1994). Introducción histórica a las teorías de la narrativa. Almería: Universidad de Almería.

. (2011). Hacia otra interpretación del poema Los reyes rojos. Martín, 24, año XI, 71-75.

Veres, L. (2011). La poesía de Eguren en Amauta. En M. Fuentes y P. Tovar (eds.), A través de la vanguardia hispanoamericana: orígenes, desarrollo, transformaciones (pp. 391-397). Tarragona: Universitat Rovira i Virgili.

Viñas, D. (2002). Historia de la crítica literaria. Barcelona: Ariel. 
Las causas de los motivos de Eguren. Bases críticas, planteamientos estéticos... / J. R. Valles C.

Wahnón, S. (1991). Introducción a la historia de las teorías literarias. Granada: Universidad de Granada.

Wellek, R. (1988). Historia de la crítica moderna (1750-1950), T. IV, La segunda mitad del siglo XIX. Madrid: Gredos.

Zuleta, E. de (1966). Historia de la crítica española contemporánea. Madrid: Gredos. 